\title{
14 Aeromobilities in Transition: From quick and dirty to slow and sexy
}

\section{Rob Bongaerts, Jeroen Nawijn, Eke Eijgelaar and Paul Peeters}

Centre for Sustainable Tourism and Transport of NHTV Breda University of Applied Sciences, the Netherlands.

\section{Introduction}

Air transport has become an important transport mode for holidays and business travel. Its growth since the 1950s has been aided by government support (e.g., infrastructure, funding) and technological innovations allowing for increases in capacity, speed and distance (Schäfer et al., 2009). The reduction of the real cost of flying has been another strong driver of the growth of air travel. In the US, for instance, real costs per passenger kilometre declined by 90\% between 1925 and 1975 (Mowery \& Rosenberg, 1981). The cost of air travel per revenue passenger-mile reduced almost continuously from $\$ 0.2692$ (constant 1978 US\$) in 1937 to \$0.0512 in 2000 (U.S. Census Bureau, 2010), a reduction of 81\%.

Aviation has grown rapidly, and remained relatively unaffected by crises in the long term. Global revenue passenger kilometres (RPK) have increased by approximately 4.5\% per year and reached more than 6 trillion RPK in 2014, having doubled since 2000. Air travel now exceeds 3 billion passengers per year, with particularly rapid growth outside of Europe and North America, with RPK growth rates of $11 \%$ for the Middle East and 8\% for Asia and the Pacific (ICAO, 2015). The International Civil Aviation Organisation (ICAO) expects another doubling of RPK, to 12 trillion, in 2030 (ICAO, 2015).

The term 'aeromobility' has been adopted to describe the increasing use and importance of airplanes (Høyer, 2000). Air transport already plays a key role in international tourism trips with a 51\% share of arrivals in 2010, growing from 38\% in 1980 (UNWTO, 2011). The International Air Transport Association (IATA) is anticipating air transport capacity to be five times bigger in 2050 compared to the year 2000 (IATA, 2013). In terms of all passenger kilometres travelled worldwide, 
Schäfer et al. (2009) expect the share of high-speed transportation (i.e. mainly air) to increase from less than $10 \%$ in 2005 to nearly $40 \%$ in 2050. In international tourism, aviation's share is expected to stabilise at approximately $52 \%$ of arrivals in 2030, yet with a doubling of arrivals compared to 2010 (UNWTO, 2011).

This rapid growth, coupled with the increasing distances travelled (Peeters, 2013), has made aviation a key contributor to travel-related carbon dioxide $\left(\mathrm{CO}_{2}\right)$ emissions. Aviation was found to contribute $40 \%$ of all global tourism $\mathrm{CO}_{2}$ emissions in 2005, which in turn made up about $5 \%$ of all anthropogenic emissions (UNWTO-UNEP-WMO, 2008). Other assessments have international and domestic civil aviation accounting for $2.1 \%$ of global $\mathrm{CO}_{2}$ emissions in 2012 (Cames et al., 2015). While this chapter is limited to carbon emissions, it is important to acknowledge that the contribution of aviation to radiative forcing is possibly far greater. For tourism it is estimated to be between $5.2 \%$ and $12.5 \%$ (Scott, Peeters, \& Gössling, 2010), due to the non- $\mathrm{CO}_{2}$ atmospheric impacts of aviation (see Lee $e t$ al., 2010). Of all transport modes, aviation emissions are growing fastest (Creutzig et al., 2015) and this is likely to continue into the future. Aviation's share in tourism emissions is estimated to grow to over $50 \%$ by 2035 (UNWTO-UNEP-WMO, 2008).

These forecasts are not compatible with sustainable international emission pathways, as proposed by the Intergovernmental Panel on Climate Change (IPCC, 2014a). In its Fifth Assessment Report (AR5), the IPCC concluded that climate impacts are already observed globally, that anthropogenic drivers have been the dominant cause of warming, and that current emission trends will lead to severe and irreversible impacts for people and ecosystems (IPCC, 2014b). Avoiding climate change is generally associated with restricting the warming of global average temperatures to no more than $2^{\circ} \mathrm{C}$ compared to the pre-industrial era, a limit that was also adopted at the United Nations Framework Convention on Climate Change (UNFCCC) $21^{\text {st }}$ Conference of Parties (COP21) in Paris (UNFCCC, 2015).

In order to fit with a low carbon pathway, Cames et al. (2015) calculate that aviation should not exceed 39\% growth by 2030 compared to 2005 emission levels, and should be $-41 \%$ compared to 2005 levels in 2050. They emphasise that more stringent targets are needed to account for non- $\mathrm{CO}_{2}$ impacts.

\section{Tourism demand \\ Cognitive dissonance}

Tourism demand typically ignores travel related carbon emissions (Hares, Dickinson, \& Wilkes, 2010; McKercher et al., 2010). Even those tourists who hold positive attitudes towards environmental protection and engage in environmentally friendly behaviour at home are generally reluctant to change their travel behaviour (Juvan \& Dolnicar, 2014). This gap, between attitudes and intention on the one hand and behaviour on the other, is generally explained through cognitive dissonance theory (Festinger, 1957) and construal-level theory (Trope \& Liberman, 2010). Construal-level theory posits that events are represented at different levels 
of mental abstraction. High-level construal refers to more distant choices, whereas low-level construal refers to more proximate choices. These choices can be in conflict with each other and cause dissonance. This dissonance creates tension which results in feelings of guilt among tourists who have high carbon footprints (e.g., Cohen, Higham, \& Cavaliere, 2011). However, this guilt has yet to affect behaviour change and it remains largely unclear as to why environmentally minded tourists refuse to make behavioural changes. We use the word 'largely' because it is obvious that individuals take holidays to de-stress, to experience pleasure, for novelty reasons, to learn something, and to have memorable experiences (e.g., Goossens, 2000; Nawijn, 2011; Tung \& Ritchie, 2011). However, there is no research that indicates that, to achieve these goals, it would be necessary to take high carbon vacations.

One reason to explain why the intention-behaviour gap exists is put forward by Eijgelaar et al. (2016), who assume that because the effect of vacationing on carbon emissions is not made visible at time of booking, for example through a carbon label - unlike attributes such as price, length of stay and destination - tourists do not take this aspect into account. The current use of eco labels or carbon labels is often ineffective, largely due to poor communication (Gössling \& Buckley, 2016).

Another line of reasoning draws from literatures on addiction, and argues of flying addicts (Cohen et al., 2011), similar to addictions to alcohol or drugs. Ram et al. (2013) offer reasons for this addiction, namely that there is an appeal in exotic destinations, which are assumed to generate greater happiness and potentially satisfy an ongoing search for novelty. Although explanations of the observed gap between intention and behaviour have their merit, these offer no solutions from the consumer side (cf. Antimova et al., 2012; Young et al., 2014).

\section{Tourism supply}

The tourism and aviation industries are facing serious challenges in reducing future carbon emissions, as it is very likely that a greater number of people will travel more, further and more frequently in the future (UNWTO, 2016). Although IATA has the ambition to keep carbon emissions at 2020 levels, the likelihood of success is low. To date, efficiency gains have been offset by the increase in volume (IATA, 2013; Peeters et al., 2016). Thus there is an urgent challenge to modify current trends and projections in such a way to avoid more, and ultimately reduce total emissions. The next section discusses three mechanisms for change: technological and operational, price, and behavioural mechanisms.

\section{Technological and operational mechanisms}

Industry bodies present a combined strategy of technology investments, more efficient operations, more effective infrastructure and positive economic measures for mitigating aviation emissions (e.g. ATAG, 2015; IATA, 2013). Technological measures that ultimately reduce emissions can be divided into two categories. The first category is related to the aircraft itself: weight, fuel efficiency and better use of the 
aircraft. The second is related to type of fuel being used. There have been many improvements in the first category, but according to IATA, more radical technological improvements can be expected by 2050 (IATA, 2013). However, Peeters et al. (2016), argue that the promise of future improvements will not succeed in achieving the necessary changes to offset the increased carbon emissions of air transport.

The second category seems more promising: the use of alternative biofuels, particularly from algae, to reduce carbon emissions. However, the success of these developments is uncertain for the mid-term, due to issues such as high associated water and/or land use, economics, and the potential for higher lifecycle GHG emissions than kerosene (Dray et al., 2012; Peeters et al., 2016). Improved operations, infrastructure, and economic measures (e.g. carbon offsets and global emissions trading) are a less important, but still serve a necessary contributing role in the industry mitigation schemes mentioned above. Yet, several studies have concluded that no combination of technological, operational and market-based measures would be sufficient to meet carbon-neutral growth or stronger reduction targets (e.g. Lee et al., 2013; Mayor \& Tol, 2010). We reason that technological and operational improvements alone will not achieve low carbon aeromobility.

\section{Price mechanisms}

\section{Direct carbon charge}

Between 1990 and 2006, European carbon emissions from aviation increased by 87\% (European Union, 2006). This was mainly due to decreasing air fares, because of low cost carriers entering the market. According to normal economic rules, a price decrease leads to an increase in demand. Therefore, in order to stop the growth of air travel, a price increase could result in lower demand. A logical step would be to internalise the external costs of aviation. Griffin and Steele (1986) explain that external costs occur when private benefits or costs differs from society's benefits or costs. Carbon emissions from air transport lead to external costs because the damages associated with aviation are borne by society instead of reflected in ticket prices. To internalise these costs we first need to know the volume of the externalised costs. Future carbon prices are very likely to increase. The US-Environmental Protection Agency estimated prices for 2015 to range from $€ 9$ to $€ 83$ (IWGSCC, 2015), while Moore and Diaz (2015) consider prices up to $€ 167$ in their study. Consequently, it is difficult to define a price. Korzhenevych et al. (2014) estimate the climate cost of 1 litre of kerosene at $€ 0.26$, which is based on IPCC emissions factors and a carbon price of $€ 90$ per ton. When we use this price to calculate the total climate related social costs of the airline industry emissions of 705 million tons in 2013 (ATAG, 2016), we come to $€ 6.3$ billion.

Taking the IATA growth scenario and the increasing carbon prices into account, this amount will increase greatly in the near future. The costs can, however, be reduced by increasing airfares significantly in order to reduce or even reverse growth of the number of miles flown. In 2015, the International Council of Clean Transportation (ICTT) calculated fuel efficiency for the transatlantic sector and 